\title{
Potential savings resulting from avoided hospitalizations and avoided productivity losses due to low influenza vaccination coverage in Poland
}

\author{
Michał Seweryn \\ Associate of the European Observatory of Health Inequalities, the President Stanisław Wojciechowski State University \\ of Applied Sciences, Kalisz, Poland
}

\begin{abstract}
Introduction: Annual vaccination against influenza can prevent $59 \%$ of influenza-related illness in healthy individuals. However, influenza vaccination coverage rate in Poland remains low, and at a rate of around 3\% it is significantly below most other European Union countries, and in particular the United Kingdom (UK), where it is above $60 \%$. The objective of this study is to analyze the potential savings for the Polish health care system based on the assumption that the influenza coverage rate in Poland would be the same as in the UK. Material and methods: The total number of influenza and influenza-like infections in 2016 in Poland stood at 4.3 million. Based on the data from the Sentinel System, we classified $41 \%$ of them as confirmed influenza cases. Influenza vaccination coverage among the general population in this period was $3.4 \%$ in Poland and $61.1 \%$ in the UK. The literature gives six categories of potential costs associated with a diagnosis of influenza. Because of poor availability of health care cost data, this study captures only part of the real influenza cost in Poland. Our model evaluated two types of potential savings associated with higher influenza vaccines rate: avoided productivity loss and avoided costs of pulmonary hospitalization connected with the influenza virus. Results: In the hypothetical scenario in which influenza coverage rate in Poland would be the same as in the UK, Poland could avoid almost 35\% of current influenza incidence, which equals over 617 thousand cases in 2016. The yearly cost of pulmonary hospitalization due to influenza in Poland was PLN 7.1 million, while the cost of productivity loss due to influenza was estimated at PLN 161.6 million. These costs added to PLN 168.7 million, or PLN 94.68 per an infected individual. We estimate the savings connected with lower productivity loss and pulmonary hospitalization frequency for Polish society, if the influenza coverage rates were on the UK level, at PLN 58.4 million.

Conclusions: The results of our analysis demonstrate that an increase in influenza vaccination coverage would generate significant economic savings for the Polish health care and social security system.
\end{abstract}

KEY WORDS: influenza, influenza vaccination, costs of flu, economic impact.

ADDRESS FOR CORRESPONDENCE: Michał Seweryn, European Observatory of Health Inequalities,

the President Stanisław Wojciechowski State University of Applied Sciences in Kalisz, 13 Kaszubska Str., 62-800 Kalisz,

Poland, e-mail: misewer@gmail.com

\section{INTRODUCTION}

The World Health Organization (WHO) estimates that between three and five million cases of severe illness and between 250,000 and 500,000 deaths occurring around the world every year are associated with influenza [1].

Influenza not only poses a serious epidemiological threat but is also a critical economic issue. For example, in the United States (US) annual direct costs of influen$\mathrm{za}$, including the cost of medications, and hospital and doctor's visits, are estimated at above $\$ 4.6$ billion. Influenza leads to a loss of approximately 17 million workdays every year among employees in the US, with an estimated cost of $\$ 7$ billion per annum in sick days and lost productivity [2]. 
Annual, seasonal influenza vaccination is the most effective public health intervention to reduce the morbidity and mortality toll of influenza, but the discussion about the cost and benefits of vaccination is still open [3] Economic impacts of seasonal influenza vary across European Union (EU) countries, but little estimation has been conducted so far for Poland, in large part due to the lack of reliable and accurate data.

Vaccination coverage is defined as the percentage of persons in a population who have received at least one dose of influenza-containing vaccine in a given season in relation to the overall population. Influenza vaccination coverage in Poland remains low, and at a rate of around $3 \%$ it is significantly below most other European Union countries [4]. On the other side of the spectrum is the United Kingdom (UK) where annual vaccination against influenza is relatively well established among the eligible population, and the coverage is at over $60 \%$.

The aim of this study is to estimate the potential and calculable savings for the Polish health care system, based on the assumption that the influenza coverage rate in Poland would be the same as in the UK. It can provide a blueprint for analysts conducting studies estimating total influenza costs in Poland, and can help guide policy makers in interpreting such studies.

\section{MATERIAL AND METHODS}

The literature gives six categories of potential costs associated with a diagnosis of influenza: inpatient hospital-

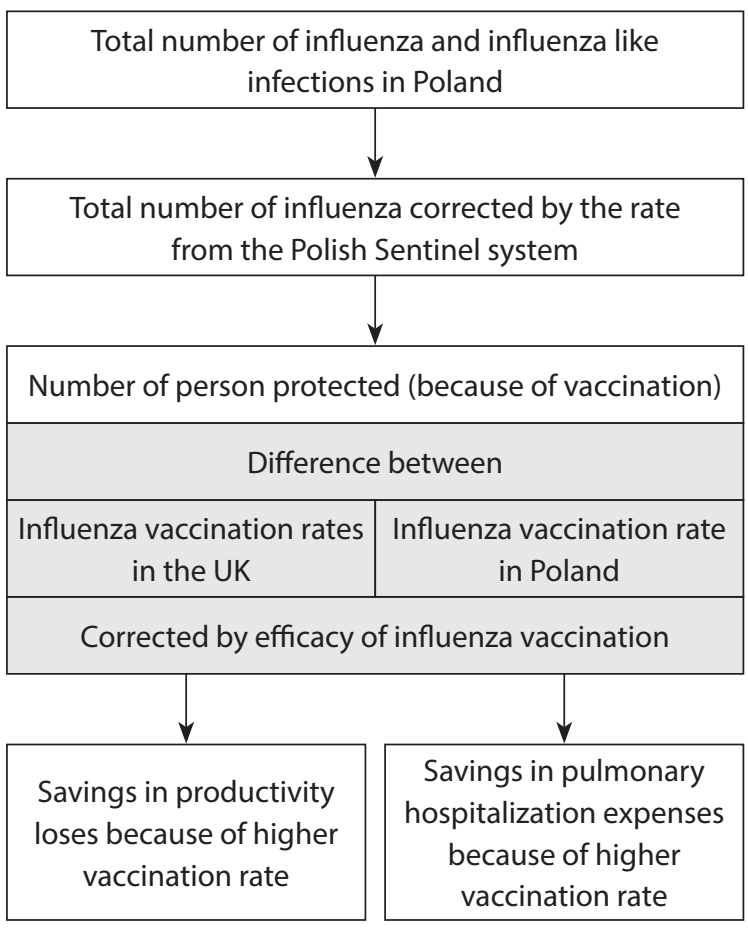

Total expected savings (TEP)

FIG. 1. Analytical framework ization, outpatient visits, self-medication, death, and productivity loss (presenteeism and absenteeism) [5]. While most medical and economic studies have evaluated influenza within high income countries, data regarding the impact of influenza in Central and Eastern Europe, including Poland, is scarce [6]. Because of very poor availability of health care cost data, this study captures only part of the real influenza costs in Poland.

An economic model was designed to evaluate two types of potential savings associated with higher, UK-level influenza vaccine coverage in Poland: avoided productivity loss and avoided costs of respiratory hospitalization related to the influenza viruses. Those were the only types of costs for which enough reliable data exist in Poland. This methodology is used to illustrate the financial benefit of higher immunization rates in Poland rather than to show cost effectiveness of influenza vaccines.

The analysis was conducted from the societal perspective in the timeframe of one year. Cost data from the latest available comparative period for Poland and the UK - 2016 - was used. This is because no data was available at the time of this study on the average value of pulmonary hospitalization in the Polish National Health Fund for the year 2017.

An overview of the analytical framework used in this study is shown in Figure 1.

The assumed model estimates total expected savings as costs avoided due to disease prevention from vaccination. Number of persons protected (NPP) by successful vaccination was calculated from the input number of individuals $\left(\mathrm{n}_{\mathrm{i}}\right)$ in the influenza infected population multiplied by the difference between coverage vaccination rates in the UK (CRUK) and in Poland (CRPL) and expected efficacy (EE) of influenza vaccines.

$$
\mathrm{NPP}=\mathrm{n}_{\mathrm{i}} \times(\mathrm{CRUK}-\mathrm{CRPL}) \times \mathrm{EE}
$$

Cost of productivity loss ( $\mathrm{Cpl})$ was calculated by using human capital approach. The human capital method is the oldest and historically most popular method of estimating the value of time losses. With this approach the value of lost productivity is considered to equal the present value of future earnings during the period of lost (or impaired) ability to work or to enjoy leisure activities [7].

The data about days of work missed because of illness come from Polish Social Insurance Institution (ZUS) and data about Gross Domestic Product and number of employees from the Polish Central Statistical Office (GUS). Work productivity loss was estimated by the total number of missed work days due to illness multiplied by average cost of working day.

An average cost of value of 1 working day is counted by using a human capital approach. The production function framework used is based on the standard specification of the Cobb-Douglas production with constant returns to scale, where potential GDP can be expressed 
formally as total output represented by a combination of factor inputs manipulated by total factor productivity (TFP) [9]. The share of labour costs in total value-added is set at 0.65 , used by the European Commission to estimate macroeconomic components [8].

Cost of pulmonary hospitalization $\left(\mathrm{C}_{\mathrm{ph}}\right)$ was calculated as number of pulmonary hospitalizations connected with influenza (identified virus) multiplied by average cost of a pulmonary hospitalization.

Unit cost $\left(\mathrm{C}_{\mathrm{u}}\right)$ for one infected person is the quotient of the sum of costs and number of individuals $\left(n_{i}\right)$ in the influenza infected population.

$$
C_{u}=\frac{C_{p l}+C_{p h}}{n_{i}}
$$

Partial expected savings (PEP) from avoided influenza cases was computed for each type of costs. Productivity loss savings were counted as a number of persons protected (NPP) multiplied by unit cost $\left(\mathrm{C}_{\mathrm{u}}\right)$.

$$
\mathrm{PEP}=\mathrm{NPP} \times \mathrm{C}_{\mathrm{u}}
$$

\section{RESULTS}

\section{NUMBER OF INFLUENZA CASES AND IMMUNISATION COVERAGE RATES}

In 2016, a total of 4,316,823 cases of influenza and influenza-like infections were reported in Poland (Table 1). In 2004, Poland implemented an influenza surveillance system called Sentinel, a selective system of integrated epidemiological and virological surveillance of influenza. The following institutions participate in the system: a representative number of family physicians, sanitary-epidemiological stations, and the National Influenza Center, NIPH$\mathrm{NIH}$, as the coordinator. The Sentinel system enables active surveillance through the collection of data from selected active sentinel sites, such as outpatient clinics, health centres, hospitals, or from individual participants, such as family physicians. Sentinel is similar to systems existing in other countries and consistent with EISS (European Influ- enza Surveillance Network). Information received from the selected sentinel sites that cover only certain parts of the population is used to assess the situation in the entire population [10].

In 2016 almost 1650 samples were tested in the Sentinel system, of which $41.08 \%$ were found positive. We estimated that a little over $41 \%$ of them were influenza cases. The coverage rate of influenza vaccination in the overall population was $3.4 \%$ in Poland [11] and $62.1 \%$ in the UK [12]. The epidemiological data presented in Table 1 were predominantly drawn from the Polish National Public Health Institute - the National Institute of Hygiene databases, and from the Public Health England [12]. Efficacy of influenza vaccination was assumed very conservatively on the 59\% rate, according to Osterholm et al. [13].

As shown in the last line of Table 1, based on the assumption that influenza coverage rate would be the same as in the UK, Poland could avoid almost $35 \%$ of influenza cases.

\section{COSTS OF PULMONARY HOSPITALISATION}

The Polish National Health Fund (NFZ) publishes very scarce data about health care utilization. Unfortunately, influenza is not an exception from that rule. The registry of the National Public Health Institute the National Institute of Hygiene contains approximately 16,000 records of hospitalization due to influenza or influenza-like illness in 2016. About $90 \%$ of them are respiratory-related hospitalization. Information from the Polish third-party payer (NFZ) is given in Table 2 .

There is a huge difference between the estimate of 16,000 hospitalization due to influenza and influenzalike infections given by the Polish public health service, and of almost 7600 pulmonary hospitalizations given by the NFZ third party payer. We therefore decided to take a conservative approach and use the lower, NFZ, estimate, for the purpose of this analysis. The average value of a pulmonary hospitalization in the 2016 Polish National Health Fund was estimated at PLN 4451.66. Table 3 presents the results of the calculations.

\begin{tabular}{|c|c|}
\hline Total number of influenza and influenza-like infections & $4,316,823$ \\
\hline Sentinel number of samples & 1,648 \\
\hline Sentinel number of confirmed influenza cases & 677 \\
\hline Percentage of confirmed influenza cases & $41.08 \%$ \\
\hline Assumed total number of influenza cases & $1,781,985$ \\
\hline Coverage rate in overall population - Poland & $3.4 \%$ \\
\hline Coverage rate in overall population - UK & $62.1 \%$ \\
\hline Number of persons protected (NPP) & $\begin{array}{c}617,155(34.63 \% \text { of total influenza cases })= \\
=1,781,985 \times(62.1 \%-3.4 \%) \times 59 \%\end{array}$ \\
\hline
\end{tabular}

TABLE 1. Number of influenza cases and immunisation coverage in 2016 in Poland 


\section{COSTS OF PRODUCTIVITY LOSS}

Data on the number of missed work days due to influenza was drawn from the Polish Social Insurance Institution (ZUS). The total number of days missed because of influenza-like illness in 2016 was 1,044,805 days. Of them, $45 \%$ were classified as influenza from identified virus and $55 \%$ as influenza-like illness from unidentified pathogen. This is why only 468,417 missed work days were taken into account in this analysis (Table 4).

\section{PARTIAL EXPECTED SAVINGS}

Total costs of product loss and pulmonary hospitalization were calculated as PLN 168,722,069. Converting this to the Unit cost, we can estimate that one infected person cost PLN 94.68. In this case, partial expected savings (PEP) connected with less productivity loss and pulmonary hospitalization frequency for the Polish society would be PLN 58,432,235, if the influenza coverage rate was on the UK level.

\section{DISCUSSION}

An important step towards evaluating the impact of influenza vaccination programmes is to determine how many infections and hospitalizations are caused by the influenza virus. This study was based on register data on cases of influenza and influenza-like infections from the National Public Health Institute - the National Institute of Hygiene. Basic data on influenza originally come from reports sent (four times in a month) to provincial sanitary and epidemiological stations by all health care units and physician practices within the Statistical Research Programme of Public Statistics (MZ-55, Report on cases and persons suspected of influenza) [14]. It is worth adding that this passive surveillance system has major limitations in terms of reporting accuracy. The Sentinel Surveillance System, in contrast, is a much better active surveillance system, but the number of samples in Poland is definitely too low (only $0.04 \%$ of all reported cases).

TABLE 2. Number of pulmonary hospitalisations due to influenza and influenza-like viruses in 2016 in Poland

\begin{tabular}{|l|c|c|}
\hline Name of hospitalisation & Number of hospitalisations & Days in hospital (mean) \\
\hline Pneumonia due to haemophilus influenzae & 611 & 7 \\
\hline Pneumonia due to identified influenza virus & 988 & 7 \\
\hline Pneumonia due to RS virus & 2718 & 6 \\
\hline Pneumonia due to other viruses & 3254 & 7 \\
\hline
\end{tabular}

TABLE 3. Cost of pulmonary hospitalisation due to influenza in Poland in 2016

\begin{tabular}{|l|c|c|c|}
\hline Name of hospitalisation & $\begin{array}{c}\text { Number of } \\
\text { hospitalisations }\end{array}$ & $\begin{array}{c}\text { Average cost of } \\
\text { hospitalisations }\end{array}$ & Total cost per year \\
\hline Pneumonia due to haemophilus influenzae & 611 & PLN 4451.66 & PLN 2,719,964 \\
\hline Pneumonia due to identified influenza virus & 988 & PLN 4451.66 & PLN 4,398,240 \\
\hline Sum & 1599 & & PLN 7,118,204 \\
\hline
\end{tabular}

TABLE 4. Costs of productivity loss due to influenza in 2016 in Poland

\begin{tabular}{|l|c|}
\hline Parameter & Value \\
\hline Poland Gross Domestic Product (GDP) in 2016 & PLN 1,858,468,000,000 \\
\hline Number of employees in Poland in 2016 & PLN 121,522 \\
\hline GDP for 1 employee in 2016 & 252 days \\
\hline Number of working days in 2016 & 229 days \\
\hline Number of working days in 2016, corrected by leave from work & 0.65 \\
\hline Correction factor (CF) & PLN 78,989 \\
\hline GDP for 1 employee in 2016 taking into account CF & PLN 345 \\
\hline Value of 1 working day in 2016 & 468,417 \\
\hline Days of work missed because of influenza & PLN 161,603,865 \\
\hline Value of productivity loss due to influenza & (15) \\
\hline
\end{tabular}


To calculate the costs we used data on the number of pulmonary hospitalization from the Polish National Health Fund (NFZ), and on the number of missed work days due to influenza from the Polish Social Insurance Institution (ZUS). While this is the best data available, it is important to keep in mind its limitations, and the fact that both databases are not error free. Despite this, we have decided to take into account source data. We believe that more conservative estimates are preferred to exaggerated assumptions which are too often used in economic research.

There is not enough reliable data about the total costs of influenza in Poland, especially costs of GP and specialists visits due to influenza, or patients' out of pocket expenses. This makes our cost calculations appear less accurate than studies that use full influenza cost-estimates based on expert opinions and own assumptions. We have therefore decided to show costs which we could justify by the use of official statistics.

\section{CONCLUSIONS}

The results demonstrate that greater influenza vaccination coverage could generate substantial economic savings for the Polish health care and social security systems. If vaccination coverage improves beyond the recently recorded level, the potential for cost savings will be significant. This research only showed part of the picture there are more direct and indirect costs involved than just pulmonary hospitalizations and the loss of productivity. There is an urgent need for further research in this field.

\section{DISCLOSURE}

The author reports no conflict of interest.

\section{References}

1. WHO influenza fact sheet no 211. Available from http://www. who.int/mediacentre/factsheets/fs211/en/ (accessed: 17 May 2018).

2. Molinari NA, Ortega-Sanchez IR, Messonnier ML, et al. The annual impact of seasonal influenza in the US: measuring disease burden and costs. Vaccine 2007; 25: 5086-5096.

3. Ciancio BC, Rezza G. Costs and benefits of influenza vaccination: more evidence, same challenges. BMC Public Health 2014; 14: 818.

4. Jorgensen P, Mereckiene J, Cotter S, et al. How close are countries of the WHO European Region to achieving the goal of vaccinating $75 \%$ of key risk groups against influenza? Results from national surveys on seasonal influenza vaccination programmes, 2008/2009 to 2014/2015. Vaccine 2018; 36: 442-452.

5. Duncan I, Taitel M, Zhang J, Kirkham H. Planning influenza vaccination programs: a cost benefit model. Cost Eff Resour Alloc 2012; 10: 10.

6. Kovács G, Kaló Z, Jahnz-Rozyk K, et al. Medical and economic burden of influenza in the elderly population in central and eastern European countries Hum Vaccin Immunother 2014; 10: 428-440.

7. Drummond MF, Sculpher MJ, Torrance GW, et al. Methods for the economic evaluation of health care programmes. $3^{\text {rd }} \mathrm{ed}$. Oxford University Press, Oxford 2005.

8. European Commission 2018 Ageing Report ISSN 2443-8014 (online) Underlying Assumptions \& Projection Methodologies. Institutional paper 065, November 2017. Available from: https://ec.europa.eu/info/sites/info/files/economy-finance/ ip065_en.pdf (accessed: 17 May 2018).

9. Havik K, Mc Morrow K, Orlandi F, et al. The Production Function Methodology for Calculating Potential Growth Rates \& Output Gaps. European Economy Economic Papers No. 535, 2014. Available from: http://ec.europa.eu/economy_finance/ publications/economic_paper/2014/pdf/ecp535_en.pdf (accessed: 17 May 2018).

10. Romanowska M, Nowak I, Rybicka I, Brydak LB. The introduction of the SENTINEL influenza surveillance system in Poland - experiences and lessons learned from the first three epidemic seasons. Euro Surveill 2008; 13: pii: 8046.

11. Antczak A, Jahnz-Różyk K, Krzywański J, et al. Rekomendacje ekspertów Ogólnopolskiego Programu Zwalczania Grypy dotyczące profilaktyki grypy w sezonie epidemicznym 2017/2018. [Recommendations provided by the experts of the All-Poland Program of Combating Influenza concerning influenza prevention in the epidemic season 2017/2018]. Fundacja Nadzieja dla Zdrowia, Warszawa 2017.

12. Seasonal influenza vaccine uptake in GP patients in England: winter season 2016 to 2017. Public Health England. Final data for 1 September 2016 to 31 January 2017. Available from: https://assets.publishing.service.gov.uk/government/uploads/ system/uploads/attachment_data/file/613452/Seasonal_influenza_vaccine_uptake_in_GP_patients_winter_season_2016_ to_2017.pdf (accessed: 17 May 2018).

13. Osterholm MT, Kelley NS, Sommer A, Belongia EA. Efficacy and effectiveness of influeza vaccines: a systematic review and meta-analysis. Lancet Infect Dis 2012; 12: 36-44.

14. Kondratiuk K, Czarkowski MP, Hallmann-Szelińska E, et al. Influenza in Poland in 2013 and 2013/2014 epidemic season. Przegl Epidemiol 2016; 70: 407-419. 